\title{
From the Other Side of the Desk: notes on teaching about race when racialised
}

\section{S. NOMBUSO DLAMINI}

\begin{abstract}
This paper examines complexities involved in the classroom application of critical pedagogy and antiracism education. It examines the concept of border crossing as a tool for progressive classroom teaching. In educational theory, difference is seen as an analytic tool that students use to examine the ways in which dominant cultures create practices of terror, inequality and exclusions. It has also been argued that through the use of difference as an analytical tool, radical educators should be able to allow students to revise what 'difference' is by crossing over into cultural boundaries that make possible narratives, languages and experiences that provide a resource for rethinking the relationship between the center and margins of power as well as between themselves and others. When teachers use 'difference' as an analytical tool, they are said to be involved in what has been loosely referred to as border pedagogy. This is a pedagogy that moves beyond the opening up of diverse cultural and historical spaces for students. It allows for an understanding of the fragile nature of identities that are transforming into borderlands characterized by different languages, voices and experiences. Drawing from the author's experiences as a Black woman teacher-educator in a predominantly white institution, the paper critically examines the limits of border pedagogy when teaching about and through 'difference', and concludes by offering suggestions for future practices in teacher education programs.
\end{abstract}

\section{Introduction}

Every day in North America, educators walk into classrooms which differ profoundly from those they attended when they were children. For some of these teachers, it is as if they experienced learning as children and young adults in a different universe from that experienced by the children they teach. No matter what a teacher's social location might be in terms of race, ethnicity, class and gender, that educator is most likely interacting on a daily basis with learners with backgrounds and experiences different from his or her own. (Dei, 1996, p. 9)

We all carry worlds in our heads, and those worlds are decidedly different. We 
educators set out to teach, but how can we reach the worlds of others when we don't even know they exist? Indeed, many of us don't even realise that our own worlds exist only in our heads and in the cultural institutions we have built to support them. (Delpit, 1993, p. xiv)

There exists an urgent need for schools and faculties of education to appropriately prepare teachers for the racial and ethnocultural diversity that exists in Canadian and other Western societies in general. Canadian immigration levels have tripled over the past decade, and the result has been that many schools have a large number of students who present a challenge to the school system. Current population trends demand that schools and faculties of education re-imagine the mainstream as intercultural and multilingual in make-up. In fact, this immigration trend is true of North America and Europe. Solomon and Levin-Rasky (1996) argue that these immigration changes have forced the Canadian Government and local school jurisdictions to develop and implement policies that directly deal with this population trend. An example of an initiative that addresses the current population trend is the Ontario anti-racism and ethnocultural equity policy. However, studies that have investigated the impact of anti-racism and multi cultural education innovations in Canadian and US schools reveal marginal teacher and administrative support for them. In fact, some studies even point towards resistance to such initiatives (see, for example, Acker, 1988; Sleeter, 1992; Solomon \& Levin-Rasky, 1996). Since teachers are the ones involved in the implementation of educational reform policies, it is important to examine their preparation for, and responses to, multiculturalism/antiracism education. For this reason, this article focuses on my experiences as an educator working primarily with teacher students who would be teaching at the secondary school level. One of the aims of documenting these experiences is to offer additional tools with which to understand reasons of teacher resistance to education reform initiatives.

There is a vast amount of literature that documents teacher resistance to innovations and changes. Solomon and Levin-Rasky (1996) argue that teacher resistance to new initiatives, and to anti-racism education in particular, results from three main factors. The first factor is traditional pedagogic concerns in which teachers interpret anti-racism education as a challenge to established teaching practices and beliefs about the function of education. The second factor has to do with conservative political views. These views are based on a belief in minority assimilation, despite evidence of the failure of this approach, and on the fear that anti-racism will privilege and provide minority students with unearned advantage over students from other groups. The third factor is based on conservative views of race and anti-racism in 
which teachers believe that a focus on anti-racism may lead to a development of racist attitudes and practices. Acker (1988) argues that resistance to new initiatives may result from a teacher's age, race, social class, and sociopolitical beliefs (values and traditions, norms and ideologies). In addition, initiatives may be seen to counteract or threaten existing programmes. Conditions of work encompassing the micropolitics of the school and the general levels of support for reform found in the school climate might also influence resistance to change. Corbett and Firestone (1987) emphasise the importance of the relationship between the proposed change and the culture of the school: 'change is greeted with suspicion and reluctance when expectations for behavior embedded in a new practice, policy or program do not coincide with existing conceptions of the way school life is or should be' (p.36).

This article builds on, and modifies, these theories of educators' responses to change. However, it is important to note that these theories are based on research conducted with teachers who are already working in the field. There is very little research conducted with student teachers to determine the nature and impact of recent teacher education programmes that emphasise critical pedagogy and antiracism/multiculturalism discourses. Some education practitioners have argued that most teachers enter their profession with little or no training in race relations, and that faculties of education do not offer courses necessary for critical training in issues of equity and social justice (see, for example, Rezai-Rashti, 1995). Teachers' subjectivities, including their norms and values, personal investments and social identities, are important in determining their willingness to be introduced to different ways of knowing and doing. This article documents the responses to anti-racist pedagogy that student teachers engage in without a full appreciation of their own position in the perpetuation of racist practices in society. The link between teachers' ideological beliefs and their classroom practices is often not fully understood in the educational community. What needs to be examined is the practicality of the expectation that teachers will engage in an anti-racist discourse without proper training and with conservative ideologies on race. As one of the student teachers I worked with rhetorically asked, 'Is it really logical to expect Hitler to teach antiracist education?'

In examining the practices of student teachers, I will draw from existing literature, my doctoral studies at the University of Toronto, and my experiences as an educator in the field. Central to the discussion of students' responses to anti-racism education and critical pedagogy is the function of power and difference. Power and difference are two concepts that significantly mediate the way students respond to me as a Black woman professor and to course materials. I analyse students' positioning of me by introducing the notion of border pedagogy, a practice that allows for an 
understanding of the fragile nature of identities that are transforming into borderlands characterised by different languages, voices and experiences.

\section{Anti-racism Education and Critical Pedagogy}

Over the past decade, the amount of literature that defines and addresses racism has increased. Most of this literature views racism as a social construct that subjects people to differential and unequal treatment on the basis of supposedly phenotypic and cultural characteristics (Khayatt, 1994; Reed, 1994; Alladin, 1996; Dei, 1996; Miles \& Torres, 1996). This literature also acknowledges that racism has undergone some changes both structurally and ideologically, which means that racialised groups can no longer use the old theories and the old strategies in order to fight against racial oppression. One can argue, then, that the racism of the last decades is more dangerous than that of the 1950s and 1960s as it is more structurally entrenched in the economic system since the globalisation of capital has led to structures that are often not recognised as racist. School is one such structure whose function makes it difficult to recognise as racist in practice.

Anti-racism education deals directly with issues of everyday racism in schools and, as such, it is often seen as a potentially revolutionary philosophy. As 'an action-oriented strategy for institutional, systemic change' (Dei, 1996, p. 25; my emphasis), anti-racism education promises to radically redefine the entire school system. In addition to being action based, anti-racism education is acclaimed for putting power relations at the centre of educational practices. Current anti-racist theory suggests that neither teachers nor students can claim to be neutral in the acquisition and utilisation of knowledge. Approaches to knowledge are influenced by daily experiences riddled with power dynamics at every level.

According to Simmons (1994) and Lee (1994), one of the strengths of anti-racism education is its ability to look beyond individual prejudice and discrimination and to examine the ways institutions support racist practices. Essed (1990) refers to this as 'institutional racism' and compares it to 'everyday racism', which she defines as the 'various types and expressions of racism experienced by ethnic groups in everyday contact with members of the more powerful (white) group' (p. 31). Within antiracist discourse, there is recognition that racist practices do not require intent (as in the common phrase, 'I did not mean it that way'), but that such practices are deemed racist in terms of their effect (Anthias \& Yuval-Davis, 1992).

Critical pedagogy and anti-racism education complement each other in that they view schools as institutions where radical ideas can be developed. Critical pedagogy sees education as essentially political. Developing critical thinking skills is crucial for the transformation of societal structures and the transformation of teaching as 
currently conceived. In the Gramscian tradition of critical pedagogues, the teacher is an intellectual committed to creating an alternative collective will [1]. This includes heeding the voices of students from minority groups, which eventually leads to the construction of new voices for liberation and democracy. Freire (1985) highlights the political aspect of critical pedagogy:

The educational proposals that I have been making for years basically derive from two rather obvious non-simplistic ideas: first, education is a political act, whether at the university, high school, primary school, or adult literacy classrooms. Second, education is a series of theories put into practice... Once we are involved in this educational practice, we also engage in a practice of knowing. (pp. 188-189)

In this sense, critical pedagogy and anti-racism education are not just about elements in a curriculum that are intended to make students aware of racism and to work toward the elimination of racist attitudes and behaviour in students. Both critical pedagogy and anti-racism education embrace the notion of raising consciousness. This consciousness regards the fact that, as presently conceived, the education system does not serve the interest of minority groups. Critical pedagogy and anti-racism education are important to those interested in educational reform. As an educator, I marry both critical pedagogy and anti-racism education in my own teaching and often see very little difference between the two. Over the years, I have come to use the phrase 'critical pedagogy' when referring to the way in which I 'do things' in the classroom. The phrase 'anti-racism education' is used more when teaching about issues of race and racism in schools and in society in general. Such differentiation is based on the order in which I was introduced to the terminology and its meaning. I was first introduced to critical pedagogy as a political educational tool. My introduction to anti-racism education only occurred in recent years. In addition, because of the length of time I have spent entrenched in critical pedagogy theories, I have become more comfortable teaching in a critical way than I am teaching in an anti-racist way. Thus, I associate the phrases 'student empowerment and voice', 'critical thinking', 'sharing power in the classroom', and 'interrogating knowledge' with critical pedagogy. This is not because such terminology is not found in anti-racism education; it is. However, for me, these terms take meaning in the practice of critical pedagogy.

Practical classroom applications of anti-racism education and critical pedagogy are in short supply. It is largely unclear how critical pedagogy and anti-racism education can be enacted in the classroom. If, for example, anti-racism education and critical pedagogy are about redefining knowledge, does this mean teachers should be 
teaching (and learning) new materials? If it is about changing the way things are done in the schools, where and how should the change occur? As an educator, I have developed my own critical classroom practices through watching those who have taught me, through reading how others do it, and through trial and error. Often, putting the principles of critical pedagogy and anti-racism into practice is very complex. For one, often it is inconsistent with classroom management. More importantly, as the following sections will demonstrate, the application of these principles can simultaneously eradicate or contradict them.

\section{The Practice of Critical Pedagogy}

My first encounter with the complexities of applying critical pedagogy in the classroom was as a doctoral student in a course on post-colonial literature co-taught by Henry Giroux and Roger Simon [2]. I had come to the Simon/Giroux course already familiar with the fundamentals of critical pedagogy based on the notion of education as a practice of freedom. More appealing to me had been Freire's challenges to the 'banking system' of education premised on the idea that all students needed to do was to absorb information given to them by knowing professors. I had found his call for liberating pedagogies, critical consciousness, and education as a practice of freedom convincing and worth embracing. Indeed, my master's thesis had used some of the Freirean concepts to investigate the possibility of applying critical liberating pedagogy within apartheid South Mrica. Thus, I had impressive book knowledge surrounding critical pedagogy: I had read Henry Giroux, Roger Simon, Jim Cummins, Peter McClaren, bell hooks, and many other critical 'pedagogists'. So, when I enrolled for the course on post-colonial literature, I was keen to see if Simon and Giroux's styles of teaching would exemplify the practices they so passionately describe in their works.

The course materials exemplified the phrase 'to challenge the canon', drawing mainly from works of those considered to be at the margins of educational scholarship. We read works by Trinh Minh-ha, Gayatri Spivak, bell hooks, Ngugi wa Thiongo, Frantz Fanon, Edward Said, and many others. The class contained students from a wide variety of ethnic backgrounds: African-Canadians, AsianCanadians, First Nations, and white Canadians. The class was conducted as a seminar and each week two or three students were assigned to do reaction papers on the prescribed readings, which they would then use to lead class discussions. We read the reaction papers at the beginning of the class, and the discussions were based on our responses to them.

Among other things, the reaction papers were designed to give voice to students' interpretations of the prescribed readings. Indeed, they were premised on the notion that meaning is socially constructed, one of the pillars of critical pedagogy. 
Discussion offered a forum where students' experiences were voiced and interrogated, another pillar of critical pedagogy. As for the role of the professors-well, the professors were to 'facilitate' the discussions and were to ensure that all voices in the classroom were heard and respected; in a nutshell, to ensure that power was evenly distributed.

One of the readings assigned for the second class was a chapter from Frantz Fanon's Black Skin White Masks (1989). In this chapter, Fanon focuses on the sexual depiction of the Black man, on what he calls the obsession of white women with Black men and the envy that Black women have for the white men [3]. Two white Canadian women and I had been assigned to respond to Fanon, responses that we photocopied and circulated to class members. I had focused my response on Fanon's depiction of the relationship between Black women and white men, discussing mainly the power relations involved. The other two women had focused on Fanon's depiction of the relationship between white women and Black men. Without remembering the details, in their response papers, both women had expressed anger at the way Fanon depicted white women, at the language he used, and at what they viewed as an insulting and stereotypical way of writing about 'others'.

The discussion began with the two women strongly restating what they had written on their papers and strongly pointing out the insulting nature of the material we had read. To say the least, I felt very uncomfortable participating, not necessarily because I disagreed with some of their concerns, but because there appeared to have been no room for any critique of the interpretation/reading that the women had set out as a framework for discussion. It was also apparent that my own response paper had been 'forgotten', sidelined, so to speak, by the way the discussion was evolving. Then an Mrican-Canadian man spoke, challenging the views that had been put forth by these two women, arguing that the text be read in its historical context, and that the two women examine the racist implications of their responses to the text. After he spoke, there was a silence that seemed to last for a very long time. We students looked at each other, then at the professor, then at each other again, and then back to the professor. After what seemed like an eternity, probably sensing the tension, the African-Canadian man stood up, mumbled something about the washroom, and left the class. At this point Giroux decided it was time for him to say something; unfortunately, I cannot recall the detail [4].

The following classes were not very different from the one I have just described. In fact, the more classes we had, the more tension there was. I vividly remember instances where, in the middle of discussion, a student would stand up angrily, say, 'Let me just say this one thing before I leave...', and then walk out of the room. I remember students crying in the midst of presentations because they felt 'attacked' by 
either the professors or other students. And I remember experiencing a marginalisation of a different kind, one that I see based on the assumption that having a voice is similar to having power. Yet, the reality of the fact was that despite the course title and description, white Canadian students were, at the very least, not ready to hear marginal voices either in text form or in person. Those students who spoke critically about Eurocentric knowledge and practices were seen by other students as 'troublemakers' and were rebuked in, inter alia, very sophisticated and intimidating language. Another problematic reality was the merging of book characters and stories with students' life experiences. White students saw themselves as representatives of the oppressors described in most of the course materials, while Indigenous and African-Canadian students viewed themselves also as representatives of the oppressed. In the end, I resorted to silence. I found power in my own silence. I was bitter about having been forced to this position. Some of my classmates pointed out to me (outside class, of course) that this position of silence was not powerful at all, that it achieved exactly what others wanted to see happening: to have me and some other 'troublemakers' quiet for a change.

Looking back at this class, I realise that it taught me more about classroom relations than any other graduate class. It was because of my experiences in it that I began to examine the meaning of the phrase 'authority of experience'. After the Simon/Giroux class, I began to examine ways in which authority of experience can be used to silence and exclude. I also came to a realisation that having 'authority over an experience' did not necessarily make one a legitimate speaker (Bourdieu, 1977). In this course and in other feminist courses I took at the graduate level, women's experiences were given voice, legitimised, and universalised. In these classes, I spoke from my own experiences as a Black woman educator, experiences that I felt were important to share, yet could not be invoked from any body of literature. Today, I struggle to hold on to the value of experience, to those nuances that only experience can avail yet not privilege these over other forms of knowing. In my classroom, I encourage students to talk about their experiences and at the same time struggle to ensure that these experiences are not given privilege over other forms of knowing and learning.

My experiences have led me to question one of the pillars of critical pedagogy: sharing power. What exactly does it mean to have students and teachers share power in the classroom? I began to question the technicality of student empowerment, of students as important members of the classroom community ready to share power with the teacher as well as with each other. I began to examine the meaning of students' empowerment and its relation to the degree of control that the teacher is comfortable relinquishing. I have concluded that what happened in the Simon/ Giroux 
class was partly a result of the professors' concern with their image as progressive white educators and their liberal illusion that freedom has no limits. As it happened, they failed the class when they refused to intervene when students exhibited racist and sexist attitudes and by accepting all ideas as relevant for classroom discussion.

Now that I occupy a position similar to that occupied by Simon and Giroux a few years ago, I have come to grasp the complexity of the teacher's position. While still critical of the role of the professors in the post-colonial course I took, I now acknowledge not only the complexities of implementing critical pedagogy in the classroom, but also the complex nature of courses that attempt to challenge existing modes of learning and teaching. I see these complexities as partly based on the composite positioning of self and 'others', on identity construction and negotiation in the classroom. In the following discussion, I document the challenges faced by racial minority educators who dare 'teach against the grain' (Simon, 1992). I use my own experience as a teacher educator to examine some of these challenges and to make suggestions for pedagogical strategies. I examine identity construction and negotiation in the process of teaching, arguing that as an ethnic minority educator, the challenges I face differ significantly from those faced by 'mainstream educators'. The analysis offered here builds on experiences of other Black women educators, notably, hooks, who has documented several challenges she faces not only from her students but also from colleagues (see, for example, hooks \& West, 1991). My aim is not to privilege challenges; rather, it is to give voice to the different experiences faced by individuals occupying the same professional position of university professor.

\section{Talking about Racial Difference from the Other Side of the Desk}

One of the concepts of critical pedagogy that I embrace and practise is the concept of power sharing, which, in a nutshell, makes students responsible for their own learning. When power is shared in the classroom, voices are given equal opportunity of expression; different critical ways of knowing and learning are validated. Through experience, I have also come to realise that validating knowledge implies the ability to invalidate certain knowledge, through, among other things, analysis and criticism. My ethnic background has helped me come to realise that sharing power with students who traditionally have always occupied positions of power is more complex when one is, for instance, teaching about and in ways that challenge existing relations of power. Let me give an example.

One of the undergraduate teacher education courses I teach is entitled 'Education across Cultural and Social Differences'. This course is about examining racial, cultural, gender, sexual orientation, and economic differences and how these 
influence the practice of teaching and learning. Over the course of teaching this course, I have come to realise that while students are willing to examine issues of sexuality, gender and class inequalities, most have problems with examining racebased inequalities. There might be multiple reasons for this problem, but here is how I have come to conceptually understand it.

First, I predominantly teach students who identify themselves as white. Here, I am aware that the concept of whiteness, like that of race, is socially constructed and burdened with at least three layers of meaning: one involves skin colour; another involves whiteness as a state of being-as lived experience constituting, among other things, unearned privileges, and a third, whiteness as an ideology, involves beliefs, policies and practices (often unarticulated) that enable whites to maintain power (Miles \& Torres, 1996). While many of the students readily recognise themselves as white by description, often they fail to acknowledge or understand the privileges granted by/through this description. In fact, white privilege is often invisible to these students and so is their participation in the ideology of whiteness. Those who actually see the relationship between whiteness and relations of power often individually distance themselves from racism through, among other things, simply laying claim to marginality because of, for example, working-class status [5].

When white students begin to learn about benefits from, and participation in, the ideology of whiteness, they respond in different ways at different phases of the course. A common response that I have found is denial. Most students believe in the myth that Canada is a 'non-racial', functionally multicultural country where people of different ethnic backgrounds enjoy the same privileges. Students who believe in this myth often go out on a limb to explain to others why what is considered a racist act might be something else. In this sense, testimonies of racism are questioned, analysed and sometimes outwardly rejected as false accusations. Statements like 'what is difficult for me to understand is that many of the events that seem like racist acts do not appear racist in any way to me' or 'to consider that act as a blatant act of racism doesn't seem justified' are common responses of denial. Commonly, students deny the racism described in testimonies by pointing out that the stated events also happen to white students. These events may include being bumped into or not being invited to 'do coffee' by colleagues (this is despite the fact that it is common knowledge that the coffee will serve as a 'debriefing' session for the staff meeting held that morning and in it will be discussed work-related issues crucial to one's success).

Another form of denial happens when students are quick to point out that they, too, have been discriminated against. Students often give accounts of gender or class discrimination and use these as models for understanding race issues. While this is a legitimate way of conceptualising experience, often the result is that the issue being 
discussed gets 'sidelined', resulting in a move to 'counterbalance' the study of racism with those issues white students feel important to them, resulting, once again, in the subordination of issues that directly affect racial minorities.

Denial also occurs when students become more concerned with projecting and maintaining a positive or non-racist self-image than the injustice of racism. A very common statement typical of this form of denial is, 'I'm not racist'. As one student wrote, 'As soon as this class started, I put myself behind a screen with the mindset that I didn't need to worry about my own belief system coming under attack because I am not racist' (emphasis added). Wellman (1977) refers to this as distancing oneself. He argues that this happens because white people view racism as tantamount to personal prejudice. When one does not 'feel' prejudiced, then racism must be someone else's problem. This individualised way of viewing racism fails to consider racism as a product of social and economic structures that benefit whites more than 'others'.

In addition to a denial, some students respond with anger, partly because they feel attacked. One student wrote, 'I think it [the class] was meant to be provoking but for many people it seemed to act as an irritant and people become offended, silent and hostile. Whether that was the desired reaction, I don't know'. When students feel attacked, they defend themselves and/or fight back. Responses to 'attacks' are eminent in some of the papers students write. The following critique of Essed's (1990) documentation of Mrican-American and German women's narration of racism exemplifies what I see as 'a fightback':

this is the problem with these cases; you only get one side of the story. What appears as racism mayor may not be. There could be personal problems between the two women that we as readers are not aware of. I need to understand the complete story in order to not say screw you [sic] to this case. All we have is a narration of a somehow angry black person whom I suspect is equally racist to white people.

Giving feedback to reaction papers like this one is difficult. On the one hand, written responses are a 'safe' way for students to vent their anger without necessarily insulting each other: the notion of you can write what you want but you have to be careful about what you say looms large in these classrooms. On the very same hand, written responses are also a way to develop a conversation between the student and the professor. They are meant to bring to the surface what Rosenberg (1997) refers to as 'underground discourses'. These are discourses of the halls, discourses that students do not bring into class out of fear that their ideas might be controversial. For instance, in the class on social and cultural difference, underground discourses often result from people's fear of being labelled racist, or from fear of revealing innermost thoughts and 
possible hurtful experiences and or potentially hurtful beliefs. In a written response, students can 'test out' their beliefs and practices in a non-confrontational way. On the other hand, however, responses such as the above can be abusive and outwardly insulting. Students can use writing to challenge the professor's authority, to vent their anger or to be vengeful. A professor in the department recently told me that he put an end to reaction papers in his bachelor Education classes because he found them very difficult to read and emotionally demanding.

Part of the anger felt by white students towards racist texts is a result of identification. To students, white is synonymous with racist and Black, First Nations, etc., is synonymous with the oppressed. A fundamental question that faces classes addressing issues of racial and other forms of subordination is how does one teach about inequality in the light of identifications? Sometimes students' anger is directed towards other classmates, those identified to be like the professor either by ideology or by racial group. This anger is more often expressed in non-verbal forms, through body language.

In addition to identifying 'others', students also identify those with whom they share beliefs and practices, a practice I call 'clique-ing'. As the class progresses, one starts to notice cliques identified by patterns of communication, ideology, space and often just social style. Patterns of communicating ideas vary within each clique. A clique constituted by those who feel angry towards the professor uses phrases like 'we hope you don't take this personally', 'we were wondering whether this is your personal experience'. Such phrases are commonly used to imply the professor's personal involvement in the issue that angers the students. In addition, this group is keen to use phrases that indicate solidarity between members and help shield away from any analysis or critique of individual subject position. Typical phrases include 'some of us are...' and 'a number of us feel that'. The underlying message is 'what I am saying now is not just my opinion, a number of $u s$ think the same way so you can't touch me because I represent $u s^{\prime}$.

Then there are those white students who begin to foster identifications across culturally constructed lines of race and gender. Often, I wonder if this is a viable political strategy, whether or not I should encourage such identifications. Harlow (1998) argues that 'identifying with' is more than just a personal moral duty; it is a political choice. For Harlow, such identifications are important whenever the dominant discourse creates a discourse of categorisation, regulating and patrolling social identities. When members seen to belong to the dominant group 'identify with' the marginalised, the boundaries of differentiation are challenged. While this might be true, personally, I find 'identifying with' problematic in that symbols of identifying with are often idealised fantasies, based not on the experiences of the marginalised but 
on the nostalgic, idealised imaginary usurpations of the dominant. Thus, in a situation of political action, for instance, ideas of those familiar with power define how action is to take place, in this way marking the imperial nature of crossidentifications, 'identifying with'.

\section{Border Pedagogy and the Experience of Difference}

Oftentimes intellectual work compels confrontation with harsh realities. It may remind us that domination and oppression continue to shape the lives of everyone, especially Black people and people of colour. Such work not only draws us closer to the suffering, it makes us suffer. (Bell Hooks, 1991, p. 164)

Giroux (1992) maps out two important ways that radical educational theorists have taken up the issue of difference. The first one centres on identity as constructed in multilayered and sometimes contradictory ways. This approach sees identities as historical and social constructs, constructs that are forever in the process of transformation and change. Thus, people occupy different subject positions at different times in their lives and for different purposes. Giroux argues that this approach to difference is limited as it fails to uncover the reasons for and process through which people take up these positions. Moreover, the conditions that make it possible for people to take up and live and speak certain discourses are equally unclear.

The second approach used by education theorists centres on differences between groups. Giroux labels this 'the discourse of identity politics'. 'This is a politics of identity that celebrates differences as they are constructed around the categories of race, class, gender and sexual preference' (p. 207)--as gay, as Jewish, as Black, etc. Giroux is equally critical of this approach, arguing that among other things, this approach promotes separatism and essentialism. In other words, this form of understanding difference often results in the privileging of certain forms of experiences of marginality, thus creating a hierarchy of oppression.

Giroux suggests that difference must be seen in three ways. First, it needs to be seen in relation to terms that link it to a broader politics. Rather than merely celebrating specific forms of difference, a politics of difference must provide the basis for extending the struggle for equality and justice to broader spheres of everyday life. This suggests that the discourse of difference and voice be elaborated within, rather than against, a politics of solidarity. By refusing to create a hierarchy of struggles, it becomes possible for critical educators to take up notions of political community in which particularity, voice and difference provide the foundations for democracy ( $\mathrm{p}$. 209).

Difference, according to Giroux, needs to be used as an analytic tool that students use to examine the ways in which dominant cultures create 'borders saturated 
in terror, inequality and forced exclusions'. Through the use of this analytical tool, radical educators should be able to allow students to rewrite difference by crossing over 'into cultural borders that offer narratives, languages and experiences that provide a resource for rethinking the relationship between the centre and margins of power as well as between themselves and others' (p. 209). Giroux refers to this kind of thinking and acting about difference as 'border pedagogy'. It is a pedagogy that moves beyond the opening up of diverse cultural and historical spaces for students. It allows for an understanding of the fragile nature of identities that are transforming into borderlands characterised by different languages, voices and experiences.

My experiences with the notion of difference differ somewhat from the above. First, classroom identities are constructed and negotiated by all parties involved, students and professor alike. The terms for constructing these identities are often self-definitive and yet hardly articulated from the other side of the boundary in that no one party says to the other, 'I want you to see me as this and that'. Even if this sometimes happens, there is no guarantee that one will be defined and identified by the features one articulates. More complex is the fact that individuals shift features of identification; what I choose to use as markers of my identity today might not be those which I chose the day before or will choose the next day; thus, leading to multiple concepts, identities and subject positions. Worse still, there is often no room for negotiating either the identities or the traits that one might choose as markers of identity. One simply 'is'. Kelly (1997, p. 108) states:

control over the signifiers of one's identity is not autonomous. Arranged in social relations of difference, signification is such that meaning can be imposed on a signifier and historically sustained through institutionalisation of discourses, which secure the structures of dominance and that govern meaning.

During my time in the classroom, I have learnt that I am caught up in what Giroux refers to as 'identity politics'. When students see me, they see a Black woman educator standing in front of them. At the beginning of each year, I am asked the same question by different groups of students: 'Where are you from?' Every year, I give a different response. The assumption made is that since I look different from them, I cannot possibly have any historical claims to the position and space that I occupy. This assumption exists despite evidence of a long history of Black community in Nova Scotia that dates back to the seventeenth century. Students' assumptions about my existence imply that, for me, participating in identity politics is not a choice but a state of being. I see my identity as multilayered (as woman, African-Canadian, professor, mother, wife etc.) but I do so with a conscious awareness of the limited 
ways in which I can 'take up' some of these subject positions.

Historically, skin colour has always been a powerful basis for determining the allocation of material and symbolic benefits and punishments in society. As an educator, I cannot simply ignore this historical practice. Consequently, when students see me, they automatically assign to me an identity that has little to do with self-chosen markers of identification, and the markers they use are not always empowered or empowering. According to Khayatt (1994, p. 7), colour 'is perceived to be a category of disadvantage'. Khayatt further asserts that this perception about colour does not just derive from bigotry but is part and parcel of the Canadian Government discourse. Kelly (1997, p. 108) affirms the institutionalised nature of markers when she argues, 'Because the symbolic order, of which language is part, is already structured on the oscillating tension of privilege and privation, some differences are historically implanted as more alienating than others within the signifying chain'. Therefore, this means that there are assumptions that I cannot take for granted, and practices I cannot engage in, in the classroom.

I value the notion of border pedagogy as a process in which the professor provides the conditions for students to engage in cultural remapping, allowing students to rewrite difference by crossing over into cultural borders that offer different narratives and that challenge the relationship between the centre and the margins. Nonetheless, this way of thinking about difference is based on a very problematic assumption. This assumption is that once the conditions are there, students will willingly engage in cultural remapping, will then cross over different cultural borders and learn different ways of thinking about the world. I have realised that the conditions I create in the classroom as a radical educator do not necessarily lead to cultural remapping. In my classes, students are free to voice their experiences, to critique and analyse course material, to debate with one another etc. The students I teach rewrite difference all right, but they often do it in a very problematic way. To them, difference becomes me. What do I mean by this?

The course I teach on cultural and social difference demands that we examine in depth the discourse of power between groups. Most of the readings I prescribe are what I have referred to earlier as 'challenging the canon' and are by authors of marginalised groups. Sometimes I bring in guest speakers to talk about how they have experienced racism, poverty, or homophobia. The results I receive from students have very little to do with border crossing. On the contrary, students stay within their borders of comfort, explain and defend their territories. Some students outwardly challenge my choice of material, pointing out lenience towards material that is 'biased against white students'. Other students outwardly challenge my authority, questioning not only decisions I make about classroom discourse but about course content. They 
question the appropriateness of certain materials, wondering if I 'read the book'. Some will ask me to do the impossible: 'prove' that a narrative was indeed motivated by racism. Such demands are often put in a way that says 'you provided these narrations because you believe in them as a Black person and therefore cannot really see their bias against white people'. Just this past year, a student asked, 'are you sure you are not saying this because you are angry at white people?' implying, of course, that I teach what I teach because I am an angry Black educator.

Border pedagogy is deceiving because it fails to examine ways in which the creation of critical pedagogy classroom conditions can result in a further marginalisation of the very discourses it aims to elevate. It also fails to ask (in any serious way) the fundamental questions about power in the classroom. It does not ask who is teaching whom and under what conditions. Accordingly, when power is shared between students and teachers, students learn better and feel empowered. They begin to view knowledge as socially constructed and to see themselves as contributors to knowledge construction. While I agree with this assertion, I think it is equally important to ask the questions, who can share power and under what conditions? More importantly, as a Black woman educator, it is imperative to ask myself the questions, how do I share power with those already in power? Is it possible to share power?

As a Black woman educator, border pedagogy means more to me than just creating certain conditions of learning. It is also about investigating the ways in which certain conditions of learning make possible the tension between embracing one's borderland and moving to another. It is about the struggle to cross over into other borderlands and remain there. It is about the transition from one's borderland to another which often results in a temporary occupation of a 'no man's land', a state where lands are not yet defined-a 'neutral state of being', so to speak. It is also about the many daily trips that individuals make across borders in order to occupy lands that are chosen through an examination of expected benefits. In other words, we should not downplay the reality of the question 'what's in it for me?'

Border pedagogy is about acknowledging that what I do in the classroom is more than an intellectual exercise, a tossing around of ideas for debate. Rather, my teaching is about challenging belief systems that are part of everyday living. This calls for an awareness that challenging belief systems is synonymous with challenging ways of living, and challenging invested territories and practices. Kelly (1997) emphasises the need to examine the relationship between culture and power. She argues for the importance of examining the benefits and losses in the process of engaging with culture. She asks, 'how are discourses engaged, negotiated, transformed by the subjects that they attempt to position? What meanings are created and 
reiterated through engagement, and with what effects?' (p. 72). I have learnt through painful experiences that border pedagogy is mainly about asking Kelly's questions. It is about social positions loaded with benefits that others would kill to safeguard. In my everyday teachings I am forever reminded about the social pleasures of being Black and the minimum benefits that come with it: the benefits of challenging others to see the world through different, albeit marginalised, lenses. As Kelly puts it:

The price of engaging our pleasures is never separate from the social cost of disordered dreams. Race is a political category, not an essential difference; middle-class values are learned, not bred; heterosexuality is common, not normal. The source and effect of our folly can be found in culture; but there, also can be found a source of hope. (p. 72) 


\section{Notes}

[1] It is the notion of 'organic Intellectuals' that is being used in a general sense here. Gramsci states, 'organic intellectuals are distinguished less by profession, which may be any job characteristic of their class, than by their function in directing the ideas and aspirations or the class to which they organically belong' (1971, p. 3).

[2] Two things are worth noting. First, because of the large number of students registered for this course, we ended up with two sections. Therefore, what I document here are reflections from one section. As students, we compared our experiences across sections. It is my understanding that most of the complexities in our section were hardly apparent in the other section. Second, it is important to note that this account is not a representation of all students' experiences in this section. It is actually accurate to state that not all students interested in Simon and Giroux's works have had a similar experience. In addition, it is important for me to note that the critique I offer here has more to do with classroom dynamics than with the declarations of critical pedagogy. I drink from the well of critical pedagogy on a daily basis.

[3] I urge you to read the chapter for yourself in order to get a full understanding of and appreciation for what happened next.

[4] The date for this class fell on a Jewish holiday and for this reason Roger Simon was not in attendance.

[5] This statement is not intended to downplay the impact of poverty on educational practices. In fact, in this course, there is a section devoted to examining different ways in which schools fail the poor. However, the point here is that often, discussions about racism and white privilege are undermined by an introduction of another 'ism', this being classism-a subject that most students are comfortable talking about and locating themselves as victims of. 


\section{References}

Acker, S. (1988). Teachers, gender and resistance, British Journal of Sociology of Education, 9, pp. 307-322.

Alladin, I. (Ed.) (1996). Racism in Canadian Schools (Toronto, Harcourt Brace Canada).

Anthias, F. \& Yuval-Davis, N. (1992) Racialised Boundaries: race, nation, gender, color and class and the antiracist struggle (New York, Routledge).

Bourdieu, P. (1977) The economics of linguistic exchanges, Social Science Information, 16, pp. 645-668.

Corbett, H. \& Firestone, W. (1987) Resistance to planned change and the sacred in school cultures, Educational Administration Quarterly, 23, pp. 36-59.

Dei, G. (1996) Antiracism Education: theory and practice (Halifax, Fernwood).

Delpit, L. (1993) Other People's Children: cultural conflict in the classroom (New York, The New Press).

Essed, P. (1990) Everyday Racism: reports from women of two cultures (Claremont, Hunter House).

Fanon, F. (1989/c. 1965) Studies in a Dying Colonialism (London, Earthscan).

Freire, P. (1985) The Politics of Education: culture, power, and liberation (South Hadley, MA, Bergin \& Garvey).

Giroux, H. (1992) Resisting difference: cultural studies and the discourse of critical pedagogy. In L. Grossberg, C. Nelson \& P. Treichler (Eds) Cultural Studies (New York, Routledge).

Gramsci, A. (1971) Selections from the Prison Notebooks (New York, International Publishers).

Hooks, B. \& West, C. (1991) Breaking Bread: insurgent Black intellectual life (Toronto, Between the Lines).

Kelly, U. (1997) Schooling Desire: literacy, cultural politics and pedagogy (New York, Routledge). Khayatt, D. (1994) The boundaries of identity at the intersection of race, class and gender, Canadian Woman Studies: Racism and Gender, 14(2), pp. 6-12.

Lee, E. (1994) Antiracist education: panacea or palliative? Orbit, 25(2), pp. 22-25.

Miles, R. \& Torres, R. (1996) Does 'race' matter? Transatlantic perspectives on racism after 'race relations'. In V. Amit-Talai \& C. Knowles (Eds) Re-situating Identities: the politics of race, ethnicity and culture (Peterborough, Broadview Press).

Reed, C. (1994) Building bridges: the antiracist dimensions of holocaust education, $\mathrm{PhD}$ dissertation, Department of Education, University of Toronto.

Rezai-Rashti, G. (1995) Multicultural education, antiracist education, and critical 
pedagogy: reflections on everyday practice. In R. Ng, P. Staton \& J. Scane (Eds) Antiracism, Feminism, and Critical Approaches to Education (Toronto, OlSE Press).

Risenberg, C. (1997) Underground discourses. In M. Fine, L. Weis, LC. Powell \& L. Mun Wong (Eds) Offwhite: readings on race, power and society (New York, Routledge).

Simmons, E. (1994) Sensitivity trainers and the race thing, New Internationalist, 20, pp. 26-27.

Simon, R. (1992) Teaching against the Grain: texts for a pedagogy of possibility (New York, Bergin \& Garvey).

Sleeter, C. (1992) Keepers of the American Dream: a study of staff development and multieultural education (London, Falmer Press).

Solomon, P. \& Levin-Rasky, C. (1996) When principle meets practice: teachers' contradictory responses to antiracist education, Alberta Journal of Educational Research, XLII, pp. 19-33.

Wellman, D. (1977) Portrait of White Racism (New York, Cambridge University Press). 